\title{
What Contributes Most to High Health Care Costs? Health Care Spending in High Resource Patients
}

\author{
Daryl Pritchard, PhD; Allison Petrilla, MPH; Shawn Hallinan, PhD; Donald H. Taylor, Jr., PhD; \\ Vernon F. Schabert, PhD; and Robert W. Dubois, MD, PhD
}

\begin{abstract}
BACKGROUND: U.S. health care spending nearly doubled in the decade from 2000-2010. Although the pace of increase has moderated recently, the rate of growth of health care costs is expected to be higher than the growth in the economy for the near future. Previous studies have estimated that $5 \%$ of patients account for half of all health care costs, while the top $1 \%$ of spenders account for over $27 \%$ of costs. The distribution of health care expenditures by type of service and the prevalence of particular health conditions for these patients is not clear, and is likely to differ from the overall population.
\end{abstract}

OBJECTIVE: To examine health care spending patterns and what contributes to costs for the top $5 \%$ of managed health care users based on total expenditures.

METHODS: This retrospective observational study employed a large administrative claims database analysis of health care claims of managed care enrollees across the full age and care spectrum. Direct health care expenditures were compared during calendar year 2011 by place of service (outpatient, inpatient, and pharmacy), payer type (commercially insured, Medicare Advantage, and Medicaid managed care), and therapy area between the full population and high resource patients (HRP).

RESULTS: The mean total expenditure per HRP during calendar year 2011 was $\$ 43,104$ versus $\$ 3,955$ per patient for the full population. Treatment of back disorders and osteoarthritis contributed the largest share of expenditures in both HRP and the full study population, while chronic renal failure, heart disease, and some oncology treatments accounted for disproportionately higher expenditures in HRP. The share of overall expenditures attributed to inpatient services was significantly higher for HRP $(40.0 \%)$ compared with the full population (24.6\%), while the share of expenditures attributed to pharmacy $(\mathrm{HRP}=18.1 \%$, full $=21.4 \%)$ and outpatient services ( $\mathrm{HRP}=41.9 \%$, full $=54.1 \%$ ) was reduced. This pattern was observed across payer type. While the use of physician-administered pharmaceuticals was slightly higher in HRP, their use did not alter this spending pattern.

CONCLUSIONS: Overall, expenditures in the HRP population are more than 10-fold higher compared with the full population. Managed care pharmacy can benefit from understanding what contributes to these higher costs, and managed care directors should consider an appropriately balanced assessment of the share of total spend by service and therapeutic category in HRP when devising drug usage and related cost-management strategies.

J Manag Care Spec Pharm. 2016;22(2):102-09

Copyright $\odot 2016$, Academy of Managed Care Pharmacy. All rights reserved.

\section{What is already known about this subject}

The top $5 \%$ of health care users based on total expenditures account for approximately $50 \%$ of all health care expenditures. The highest expenditure category by place of service for the full population is outpatient care.

Expenditures for high resource patients (HRP) attributed to inpatient care/hospitalizations are significantly higher than in the full population.

\section{What this study adds}

Spending patterns for HRP differ considerably from the general population of managed care enrollees.

The share of overall expenditures attributed to inpatient services was significantly higher for HRP compared with the full population, while the shares of expenditures attributed to pharmacy and outpatient services were reduced.

Pharmaceutical costs do not impact the higher spending in HRP as much as inpatient expenditures, and injectable/infusible treatments represent only a minor part of high resource patient health care expenditures despite greater physician-administered pharmacy use.

T S. health care spending nearly doubled in the decade from 2000-2010, and the rate of growth of health care costs is expected to be higher than the growth in the economy for the near future. Although the pace of increase has moderated recently, there is broad agreement that the rise in costs must be controlled. ${ }^{1-5}$ However, there is disagreement over which components of spending are the most problematic. ${ }^{6}$ The distribution of health care expenditures shows that over $50 \%$ of costs can be attributed to outpatient services, while less than $25 \%$ of costs can be attributed to either pharmacy or inpatient services. ${ }^{7,8}$ However, a focus on the average rate of health care utilization ignores the vast variation in individual patient use. Previous studies have estimated that $5 \%$ of patients account for half of all health care costs, while the top $1 \%$ of spenders account for over $27 \%$ of costs. ${ }^{9-11}$ Patients in the highest spending groups tend to have a higher incidence of chronic conditions and, in general, use more health care resources than other patients. ${ }^{10,12}$ The distribution of health care expenditures by place of service and the prevalence of particular health 
TABLE 1 Baseline Characteristics of Study Sample

\begin{tabular}{|c|c|c|}
\hline Characteristic & $\begin{array}{c}\text { All Patients } \\
(\mathrm{N}=15,587,257)\end{array}$ & $\begin{array}{c}\text { High Resource } \\
\text { Patients } \\
(\mathrm{N}=779,364)\end{array}$ \\
\hline \multicolumn{3}{|l|}{ Age (years) } \\
\hline Mean (SD) & $34.7 \quad(19.5)$ & $(16.5)$ \\
\hline Median & 36 & 52 \\
\hline \multicolumn{3}{|l|}{ Age group (\%) } \\
\hline$<8$ years & 26.2 & 6.0 \\
\hline $18-34$ years & 21.7 & 13.9 \\
\hline $35-44$ years & 14.6 & 14.0 \\
\hline $45-54$ years & 18.4 & 24.7 \\
\hline 55-64 years & 17.0 & 34.9 \\
\hline $65+$ years & 2.0 & 6.6 \\
\hline \multicolumn{3}{|l|}{ Gender (\%) } \\
\hline Female & 47.9 & 40.6 \\
\hline Male & 52.1 & 59.4 \\
\hline \multicolumn{3}{|l|}{ Geographic region (\%) } \\
\hline Northeast & 15.6 & 14.8 \\
\hline Midwest & 33.6 & 37.4 \\
\hline South & 40.7 & 39.1 \\
\hline West & 10.0 & 8.6 \\
\hline \multicolumn{3}{|l|}{ Health plan type (\%) } \\
\hline $\mathrm{PPO}$ & 68.8 & 67.9 \\
\hline $\mathrm{HMO}$ & 20.2 & 19.8 \\
\hline Other & 11.1 & 12.3 \\
\hline Payer type (\%) & & \\
\hline Private commercial & $88.9(\mathrm{~N}=13,858,466)$ & 87.6 \\
\hline Medicaid managed care & $8.8 \quad(\mathrm{~N}=1,378,052)$ & 4.9 \\
\hline Medicare Advantage & $2.3 \quad(\mathrm{~N}=350,739)$ & 7.5 \\
\hline Charlson Comorbidity In & $\mathrm{ex}(\%)$ & \\
\hline 0 & 88.2 & 58.8 \\
\hline 1 & 7.7 & 18.2 \\
\hline 2 & 2.7 & 11.1 \\
\hline $3+$ & 1.4 & 11.9 \\
\hline Mean (SD) & $0.2 \quad(0.7)$ & $1.0 \quad(1.6)$ \\
\hline Median & 0 & 0 \\
\hline Duration of follow-up in & Y2011 (days) & \\
\hline Mean (SD) & $338.2 \quad(76.3)$ & $351.3 \quad(50.3)$ \\
\hline Median & 365 & 365 \\
\hline $\begin{array}{l}\text { Enrolled for the full } \\
\text { CY2011 (\% yes) }\end{array}$ & 85.5 & 89.9 \\
\hline
\end{tabular}

conditions for these high resource patients (HRP) is not clear, and is likely to differ from the overall population.

As concern about U.S. health care spending continues to rise, pharmaceutical costs are often the subject of great attention. ${ }^{6,13,14}$ The advent of specialty biopharmaceuticals has garnered particular focus in the health spending debate, and many believe that health care costs are rising because of pharmaceutical expenditures in high cost patients. ${ }^{15-18}$ However, the appropriate use of pharmaceuticals is also largely believed to be able to improve health and potentially reduce the need for other medical services. ${ }^{19,20}$ These potential benefits may have an even greater impact on the HRP population. There is a need to examine the spending patterns of HRP compared with the full population to better understand the components of health care expenditures, including specialty pharmaceuticals, which drive overall spending.

The purpose of this study was to examine health care expenditure distribution in a large U.S. managed care population. HRP was classified as the subset of patients whose expenditures per year were in the top 5\%. Spending patterns were compared across place of service and payer type to determine in which areas resources were most used. Physician-administered pharmacy expenditures were examined in particular to assess the impact of their use on HRP expenditures and to determine the top health conditions by spend in this population.

\section{Methods}

\section{Data Source}

Data for this retrospective analysis were obtained from the IMS LifeLink Health Plan Claims (HPC) Database, which includes fully adjudicated medical and pharmaceutical claims for 74 million unique patients from more than 80 U.S. health plans. The characteristics of the database have been reported in previous studies..$^{21,22}$ A description of cohort selection and measures is also included as supplementary material.

\section{Cohort Selection}

Patients of all ages enrolled in managed care health plans on January 1, 2011, with at least 180 days of continuous enrollment (CE) prior to this date (for analysis of baseline comorbidities) were included. No minimum follow-up was required to ensure that severely ill patients with limited follow-up or high expenditures would not be excluded, but patients who experienced gaps in enrollment greater than 30 days during the variable follow-up period were excluded to ensure that complete claims were present for each patient. Study attrition is shown in Table 1.

\section{Statistical Analysis}

Baseline demographics included age, sex, geographic region, health plan type (preferred provider organization, health maintenance organizaiton, or other), and payer type (commercial, Medicare Advantage, or Medicaid managed care). The Charlson Comorbidity Index (CCI, Dartmouth-Manitoba adaptation), a weighted summary of severe acute and chronic conditions, was calculated over the 180 days before January 1, 2011, and used as a proxy measure for patients' clinical severity. ${ }^{23}$

The primary endpoint for this analysis was the comparison of expenditures for HRP with the full population. All-cause direct health care expenditures were captured for calendar year 2011. Allowed expenditures were summed for each service record, which reflects the total amount of reimbursement for 


\begin{tabular}{|c|c|c|c|c|c|c|c|c|}
\hline \multirow[b]{2}{*}{ Setting of Care } & \multicolumn{4}{|c|}{$\begin{array}{c}\text { All Patients } \\
(\mathrm{N}=15,587,257)\end{array}$} & \multicolumn{4}{|c|}{$\begin{array}{l}\text { High Resource Patients } \\
(\mathrm{N}=779,364)\end{array}$} \\
\hline & $\begin{array}{c}\% \text { of Mean } \\
\text { Total } \\
\text { Expenditures }\end{array}$ & Mean (\$) & SD (\$) & Median (\$) & $\begin{array}{c}\% \text { of Mean } \\
\text { Total } \\
\text { Expenditures }\end{array}$ & Mean (\$) & SD (\$) & Median (\$) \\
\hline $\begin{array}{l}\text { Total direct all-cause expenditures } \\
\text { (2012 U.S. \$) }\end{array}$ & 100.0 & 3,955 & 16,122 & 709 & 100.0 & 43,104 & 58,518 & 26,796 \\
\hline Total inpatient expenditures & 24.6 & 972 & 10,509 & 0 & 40.0 & 17,239 & 43,720 & 0 \\
\hline Total outpatient expenditures & 54.1 & 2,139 & 7,683 & 506 & 41.9 & 18,063 & 28,700 & 12,770 \\
\hline $\begin{array}{l}\text { Ambulatory surgical center, dialysis, } \\
\text { physical therapy, and other } \\
\text { outpatient services }\end{array}$ & 19.7 & 781 & 5,541 & 23 & 20.3 & 8,739 & 22,962 & 3,465 \\
\hline Outpatient office visits & 11.7 & 462 & 1,605 & 218 & 4.9 & 2,117 & 6,506 & 1,296 \\
\hline Physician fees for surgical services & 7.0 & 278 & 1,578 & 0 & 5.6 & 2,406 & 6,005 & 531 \\
\hline Radiology & 6.9 & 271 & 1,819 & 0 & 6.0 & 2,565 & 7,487 & 759 \\
\hline ED visits & 4.5 & 177 & 1,019 & 0 & 2.7 & 1,148 & 3,686 & 0 \\
\hline Lab and pathology & 4.3 & 170 & 751 & 12 & 2.5 & 1,088 & 2,939 & 449 \\
\hline Total pharmacy expenditures & 21.4 & 845 & 5,314 & 30 & 18.1 & 7,803 & 22,047 & 2,079 \\
\hline Retail/mail order pharmacy scripts & 18.6 & 734 & 4,156 & 24 & 13.6 & 5,854 & 17,065 & 1,605 \\
\hline Injectable/infusible treatments & 2.8 & 112 & 3,092 & 0 & 4.5 & 1,949 & 13,679 & 0 \\
\hline
\end{tabular}

health care services (i.e., amount paid by the insurer plus the plan member's out-of-pocket share, including those with $\$ 0$ expenditures). Enrollees whose total health care expenditures for calendar year 2011 were above the 95th percentile were defined as HRP. This stratification was repeated within each payer type.

Expenditures within each services/settings of care were calculated as follows: (a) inpatient services (hospitalizations, skilled nursing facility stays); (b) outpatient pharmacy expenditures (prescription drugs issued by retail/mail-order pharmacies and physician-administered injection/infusion treatments); and (c) outpatient services such as physician office visits, emergency department (ED) visits, laboratory/pathology, radiology, physician fees for surgical services, ambulatory surgery center (ASC), and all other unclassified services. Expenditures were inflated to March 2015 U.S. dollars using the medical care component of the U.S. Consumer Price Index. Expenditures were calculated for all plan members (regardless of service) and then separately for plan members with at least 1 claim for that level of service. The number, total days, and average length of stay of inpatient hospitalizations for calendar year 2011 were also captured.

Expenditures for each inpatient/outpatient service or physician-administered treatment were mapped to 1 of 285 clinically homogenous Agency for Healthcare Research and Quality (AHRQ) Clinical Classifications Software (CCS) diagnostic categories using the diagnosis code in the first position on each record. ${ }^{24}$ Unlike the primary data collection and analysis for this study described above, expenditures for retail/mail order medications for this CCS health condition category spending analysis were excluded due to absence of diagnosis codes on pharmacy transaction records. Total expenditures for each CCS grouping were summed and the percentage of total expenditures attributable to each CCS category was calculated.

Descriptive and summary statistics were used to describe the baseline demographic characteristics and primary study outcomes. The sample sizes range in the hundreds of thousands to millions, which provides clear statistical sensitivity/ power. Results are reported for the full study population, for the top 5\% of spenders, and by payer type. Analyses were performed using SAS version 9.1 (SAS Institute, Cary, NC).

\section{Results}

\section{Sample Demographics}

A total of $15,587,257$ health plan members met the selection criteria, and 779,364 were classified as HRP. Table 1 shows the demographic characteristics for the full study population and for HRP. The majority of plan members were enrolled in private commercial health plans (88.9\%). The mean age was 48.2 years for the HRP compared with 34.7 years for the full study population. Comorbidities were observed in $41.2 \%$ of the HRP (CCI rating $>0$ ) compared with $11.8 \%$ of the full study population. Among the full study population, $4.1 \%$ of patients had at least 1 inpatient stay in calendar year 2011 compared with $49.7 \%$ of HRP. While study subjects had variable periods of follow-up, $85.5 \%$ of the full study population was enrolled in the health plan for the full calendar year 2011. 


\section{FIGURE 1 Breakdown of Prescription Expenditures}

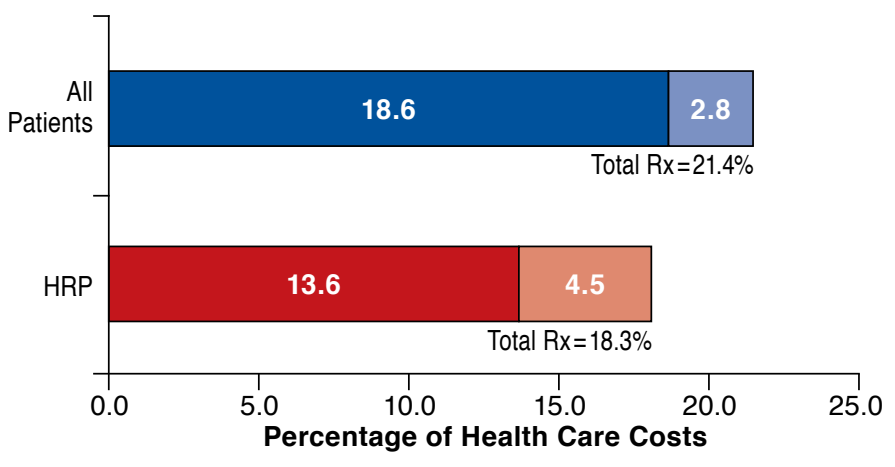

Prescriptions Injectable/Infusable

$H R P=$ high resource patients; $R x=$ prescription

\section{High Resource Patient Expenditures}

Total direct health care expenditures and distributions of expenditures by place of service for the full population and HRP are reported in Table 2. HRP accounted for $54.5 \%$ of the total health care expenditures. The mean total expenditure per HRP was $\$ 43,104$ versus $\$ 3,955$ per patient for the full population. The mean inpatient expenditures for HRP were $\$ 17,239$ per patient, accounting for $40.0 \%$ of all expenditures in this cohort, compared with the mean inpatient expenditures for all patients in the full population (\$972 per patient, $24.6 \%)$. The mean dollar amounts for outpatient and pharmacy expenditures are higher in HRP than in the full population, however, because inpatient costs are so much greater in HRP compared with the full population; this translates to the outpatient and pharmacy expenditures making up a much smaller share of HRP expenditures. The mean outpatient expenditures accounted for $41.9 \%$ of all expenditures for HRP $(\$ 18,063$ per patient), compared with $54.1 \%$ ( $\$ 2,139$ per patient) for the full population. HRP outpatient expenditures were driven largely by ASC, which accounted for $20.3 \%$ of overall expenditures compared with $19.7 \%$ in the full population, while HRP physician office (4.9\%) and emergency room visits (2.7\%) were a lower percentage of overall expenditures when compared with the full population ( $11.7 \%$ and $4.5 \%$, respectively). Pharmacy expenditures made up only $18.1 \%$ of all health care expenditures in HRP ( $\$ 7,803$ per HRP) compared with $21.4 \%$ of expenditures ( $\$ 845$ per patient) in the full population.

The breakdown of pharmacy expenditures between retaildispensed versus physician-administered medications is shown in Figure 1. Overall pharmacy expenditures account for 21.4\% of all health care expenditures in the full study population and $18.1 \%$ of all health care expenditures for the HRP. Physician- administered treatments accounted for only $2.8 \%$ of overall expenditures (mean $\$ 112$ [interquartile range $(\mathrm{IQR})=\$ 0$ ] per patient), and $4.5 \%$ of expenditures among HRP (mean $\$ 1,949$ per patient $[\mathrm{IQR}=\$ 68]$ ).

Spending distributions by place of service differ in magnitude, but not in direction, among the 3 payer types in the study population (commercially insured, Medicare Advantage, and Medicaid managed care; Figure 2). In general, the share of expenditures attributed to inpatient services was higher in HRP compared with the full population, while the share of expenditures attributed to outpatient and pharmacy products and services were lower.

Top 20 Health Conditions by Spend in High Resource Patients The top 20 CCS categories based on contribution to total health care expenditures for HRP are shown in Table 3. Of the 285 CCS categories, services attributable to the top 20 categories account for $39 \%$ of total direct health care expenditures in the HRP population and 32\% of expenditures for all patients. Back disorders and osteoarthritis contribute the largest share of expenditures in both the full study population and the HRP. Chronic renal failure, heart disease, and some oncology treatments consume the next largest share of expenditures among HRP while other connective tissue diseases, heart disease, and unclassified residual clinical services consume the next largest share of expenditures in the full study population. The health conditions whose share of expenditures was disproportionately largest in HRP compared with the full study population include: chronic renal failure, maintenance chemotherapy and radiotherapy, breast cancer, implant complications, rehabilitation care, myocardial infarction, and septicemia. These clinical categories have a significantly higher prevalence in the HRP population. Among these conditions, only chemotherapytreated cancer is heavily driven by drug expenditures, whereas most of the other conditions are dominated by expenditures in the inpatient and outpatient facility settings.

\section{Discussion}

Analysis showed that the spending pattern for HRP differs considerably from the general population of managed care enrollees. Overall, expenditures in this population are more than 10-fold higher compared with the full population. Although absolute expenditures for each place of service are increased, the share of spending on inpatient services is significantly higher in HRP, while the share of expenditures attributed to major outpatient places of service and pharmacy are lower. While some common health conditions, such as back disorders and osteoarthritis, contribute to the largest share of expenditures in both the HRP and overall populations, other conditions such as chronic renal failure, graft rejection, and some cancers accounted for disproportionately higher expenditures in HRP. These health conditions are often associated 


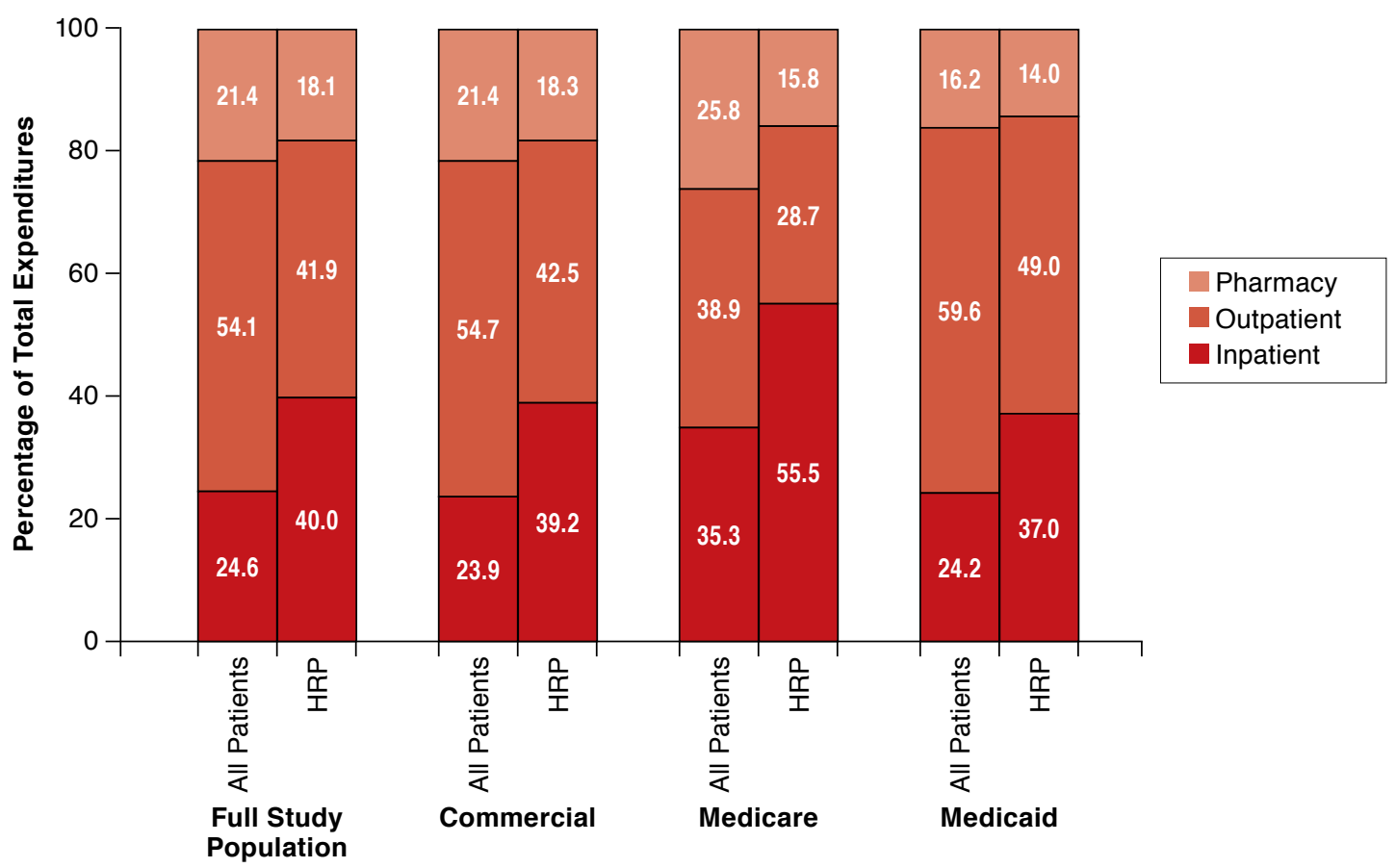

HRP = high resource patients

with increased hospitalizations, and/or disabilities. Managed care pharmacists should consider the spending pattern across service type in HRP, and appropriately account for disproportionately higher prevalence conditions when designing medication management strategies.

Although pharmaceutical expenditures are higher in HRP compared with the full population, these costs do not impact the overall increase in HRP health care spending as much as inpatient expenditures. A report from the Congressional Budget Office (CBO) estimated that a $1 \%$ increase in pharmaceutical use would cause Medicare spending on medical services to fall $0.2 \%{ }^{19}$ Furthermore, policies featuring strict drug utilization control may have the unintended effect of increasing expenditures in more expensive service settings. For example, schizophrenia patients receiving limited choices of antipsychotic medications experienced significantly higher numbers of overall and schizophrenia-related hospitalizations within 1 year compared with those who had unrestricted treatment options. ${ }^{25}$ This suggests that appropriate medication management has the potential to bring down overall health care costs by helping to reduce hospitalizations and disabilities.

Specialty drugs often come at a greater expense, but also are often associated with improved clinical benefits and/or increased patient-specific efficacy. A recent study showed that appropriate specialty biopharmaceutical use could reduce overall costs. ${ }^{20}$ Despite growing attention to their costs, research shows that injectable/infusible treatments represent only a relatively minor part of HRP health care expenditures despite greater physician-administered pharmacy use. Blunt efforts to limit access to these medications could actually have a negative impact on overall expenditures..$^{15,26}$

\section{Limitations}

This analysis reflects the U.S. population covered in managed health care plans, excluding uninsured patients and patients enrolled in traditional Medicare and Medicaid feefor-service (FFS) plans. The results are most generalizable to similar commercial health insurance plan populations and may differ from Medicare and Medicaid fee-for-service subpopulations. Previous research showed that Medicare managed care patients have lower expenditures compared with traditional Medicare FFS enrollees.,26 Thus, these results most accurately reflect commercial payer perspectives. The inclusion of Medicare FFS beneficiaries would likely reduce the relative share of pharmaceuticals in HRP due to the Part D "donut hole" and higher hospitalization rate. Thus, analysis may underestimate inpatient expenditures and overestimate pharmacy expenditures. ${ }^{27}$ 


\section{TABLE 3 Top 20 Diagnosis/Procedure Groupings Based on Total Plan Expenditures in CY2011}

\begin{tabular}{|c|c|c|c|c|c|c|}
\hline \multicolumn{2}{|c|}{$\begin{array}{l}\text { CCS Rank (Based on } \\
\text { Contribution to Total } \\
\text { Plan Expenditures) }\end{array}$} & \multirow[b]{2}{*}{ AHRQ CCS Category } & \multicolumn{2}{|c|}{$\begin{array}{l}\text { CCS Category as } \\
\text { Percentage of Total Plan } \\
\text { Expenditures }\end{array}$} & \multicolumn{2}{|c|}{$\begin{array}{l}\text { Percentage of Patients } \\
\text { with 1+ Service Claim } \\
\text { in CCS Category }\end{array}$} \\
\hline HRP & $\begin{array}{c}\text { All } \\
\text { Patients }\end{array}$ & & $\begin{array}{c}\text { HRP } \\
(\%)\end{array}$ & $\begin{array}{l}\text { All Patients } \\
(\%)\end{array}$ & $\begin{array}{c}\text { HRP } \\
(\%)\end{array}$ & $\begin{array}{l}\text { All Patients } \\
(\%)\end{array}$ \\
\hline 1 & 1 & Spondylosis, intervertebral disc disorders, other back problems & 5.04 & 4.87 & 28.74 & 9.23 \\
\hline 2 & 2 & Osteoarthritis & 3.44 & 2.30 & 13.67 & 2.71 \\
\hline 3 & 10 & Chronic renal failure & 2.67 & 1.58 & 3.68 & 0.41 \\
\hline 4 & 4 & Coronary atherosclerosis and other heart disease & 2.63 & 1.78 & 11.29 & 1.70 \\
\hline 5 & 14 & Maintenance chemotherapy, radiotherapy & 2.61 & 1.52 & 3.24 & 0.20 \\
\hline 6 & 12 & Cancer of breast & 2.46 & 1.54 & 3.71 & 0.58 \\
\hline 7 & 18 & Complication of device, implant or graft & 2.14 & 1.30 & 4.93 & 0.40 \\
\hline 8 & 17 & Rehabilitation care, fitting of prostheses, and adjustment of devices & 2.01 & 1.36 & 8.39 & 1.03 \\
\hline 9 & 24 & Acute myocardial infarction & 1.67 & 0.99 & 1.93 & 0.17 \\
\hline 10 & 25 & Septicemia (except in labor) & 1.60 & 0.96 & 1.88 & 0.16 \\
\hline 11 & 20 & Cardiac dysrhythmias & 1.51 & 1.21 & 11.73 & 2.46 \\
\hline 12 & 3 & Other connective tissue disease & 1.47 & 1.98 & 30.75 & 9.30 \\
\hline 13 & 16 & Other nervous system disorders & 1.44 & 1.41 & 17.24 & 3.36 \\
\hline 14 & 21 & Biliary tract disease & 1.35 & 1.15 & 4.64 & 0.78 \\
\hline 15 & 33 & Complications of surgical procedures or medical care & 1.32 & 0.81 & 5.59 & 0.66 \\
\hline 16 & 8 & Nonspecific chest pain & 1.25 & 1.63 & 18.20 & 4.26 \\
\hline 17 & 5 & Residual codes, unclassified & 1.18 & 1.70 & 28.89 & 7.49 \\
\hline 18 & 7 & Abdominal pain & 1.09 & 1.64 & 22.02 & 6.23 \\
\hline 19 & 22 & Mood disorders & 1.07 & 1.14 & 10.89 & 4.11 \\
\hline 20 & 34 & Other nutritional, endocrine, and metabolic disorders & 1.04 & 0.78 & 8.10 & 3.12 \\
\hline
\end{tabular}

The component of expenditures due to pharmaceuticals (21.4\%) exceeds those reported in other sources (typically ranging from 12\%-18\%) because the analysis included physicianadministered drugs in the pharmacy expenditure category, while other studies limit drug costs to retail pharmacy costs. ${ }^{6}$ Overall expenditures reported in this study are generally lower than other reports $(\$ 3,955$ per patient compared with $\$ 8,680$ per patient) because the study database contains only reimbursable (claims-related) expenditures, whereas studies using claims data for smaller populations include other cost components such as administrative, dental, home health, long term, and hospice care. ${ }^{28}$ The exclusion of nonreimbursable costs from the analysis reduces overall expenditures by more than $50 \%$ compared with other reports. A lack of Medicare and Medicaid FFS data, including dual eligibles, also leads to an underestimation of expenditures by excluding the oldest, sickest population segment.

The analysis of specialty pharmaceuticals is limited to injectable/infusible medications that are administered by a health care provider. Self-administered or non-injectable specialty medications are included in the retail/mail-order pharmacy expenditures. While retail/mail-order specialty medications represent a very small portion of overall specialty drug use, the analysis does not provide a perfect breakdown of specialty versus non-specialty pharmaceuticals.
The use of the AHRQ CCS categories allow researchers to aggregate clinical data into clinically meaningful categories; however, there is likely some level of misclassifications or expenditure misallocations due to comorbid conditions, as well as undetected expenditure attributions for diagnoses not listed on the claim. Also, the CCS taxonomy does not categorize retail/mail order pharmacy spending, whose claims do not include diagnosis codes.

\section{Implications}

With over $50 \%$ of expenditures being incurred by only $5 \%$ of patients, directing cost-reduction efforts outside of this group can only have limited effects. Patients that fall into the category of HRP change each year depending on the stage of their health condition and the state of their health care. However, a better understanding of the distribution of expenditures across service type and the magnitude for which certain health conditions have higher prevalence in the HRP population may allow managed care pharmacists to better consider strategies to improve HRP outcomes and reduce health care costs.

Roughly $50 \%$ of HRP had at least 1 hospitalization compared with less than $5 \%$ in the full population. Consequently, inpatient services make up a higher share of overall expenditures and are the primary contributor to higher health care costs 
in HRP. Conversely, pharmaceuticals are more widely used across the general population and have a lower cost impact on the most expensive patients. This spending pattern was seen in all subpopulations regardless of the type of insurer, but is most pronounced in the Medicare subgroup, thereby having potentially farther-reaching implications as the U.S. population ages. To have the greatest impact on potentially bringing down health care costs, drug management programs will need to focus on how best to affect a reduction in inpatient admissions and improvement in outcomes at lower cost in HRP.

\section{Conclusions}

$\overline{\text { Understanding spending patterns in HRP, including resource }}$ utilization across place of service and prevalence of conditions, may help to appropriately devise medication management strategies. Pharmaceutical spending is an important part of the health care-spending picture, but it is not the predominant contributor to higher spending in HRP. A primary goal of health care cost reduction efforts needs to be reducing hospitalizations. Assuring the appropriate use of medicines in some cases may alter or reduce progression of disease. Moving forward, managed care pharmacy should consider the distribution of expenditures across place of service as well as the health conditions that are disproportionately more prevalent in HRP when devising resource utilization policies.

\section{Authors}

DARYL PRITCHARD, PhD, is Vice President, Science Policy, Personalized Medicine Coalition, Washington, DC; ALLISON PETRILLA, MPH, is Director, Health Economics and Outcomes Research, Avalere Health, Washington, DC; DONALD H. TAYLOR, $J R, P h D$, is Associate Professor, Duke Sanford School of Public Policy, Durham, North Carolina; and ROBERT W. DUBOIS, MD, PhD, is Chief Science Officer and Executive Vice President, National Pharmaceutical Council, Washington, DC. SHAWN HALLINAN, $\mathrm{PhD}$, is Statistical Programmer, IMS Health, Alexandria, Virginia, and VERNON F. SCHABERT, PhD, is Senior Research Scientist, Evidera, Bethesda, Maryland.

AUTHOR CORRESPONDENCE: Robert W. Dubois, MD, PhD, Chief Science Officer, National Pharmaceutical Council, 1717 Pennsylvania Ave., NW, Ste. 800, Washington, DC 20006. Tel.: 202.827.2100; E-mail: rdubois@npcnow.org.

\section{DISCLOSURES}

Funding for this study was contributed by the National Pharmaceutical Council, an industry-funded health policy research organization that is not involved in advocacy or lobbying. Hallinan is employed with IMS Health, and at the time of this study, Petrilla and Schabert were employed with IMS Health, which received consulting fees from the National Pharmaceutical Council. Dubois is employed with the National Pharmaceutical Council, and Pritchard was employed with the National Pharmaceutical Council, at the time of this study. Taylor has nothing to disclose.
Study concept and design were contributed by Pritchard, Taylor, DuBois, and Schabert, with assistance from Petrilla. Petrilla, Hallinan, and Schabert collected the data, which were interpreted by Pritchard, Taylor, Schabert, and DuBois. The manuscript was primarily written by Pritchard, with assistance from Petrilla, Taylor, Schabert, and DuBois, and revised by Pritchard and Dubois, with assistance from Schabert and Petrilla.

\section{ACKNOWLEDGMENTS}

The authors wish to acknowledge Adam Lustig, MS, Senior Manager, Health Policy, The Advisory Board Company, Washington, DC, for his editorial contribution to the writing and revising of the manuscript.

\section{REFERENCES}

1. Centers for Medicare \& Medicaid Services (CMS). National health expenditures projections, 2014-2024. July 2015. Available at: https://www.cms. gov/research-statistics-data-and-systems/statistics-trends-and-reports/ nationalhealthexpenddata/nationalhealthaccountsprojected.html. Accessed December 9, 2015.

2. Martin AB, Hartman M, Whittle L, Catlin A; the National Health Expenditure Accounts Team. National health spending in 2012: rate of health spending growth remained low for the fourth consecutive year. Health Aff (Millwood). 2014;33(1):67-77.

3. Centers for Medicare \& Medicaid Services (CMS). National health expenditures; aggregate and per capita amounts, annual percent change and percent distribution: selected calendar years 1960-2014. 2015. Available at: https://www.cms.gov/research-statistics-data-and-systems/statistics-trendsand-reports/nationalhealthexpenddata/nationalhealthaccountshistorical. html. Accessed December 9, 2015

4. Goodell S, Ginsburg PB. High and rising health care costs: demystifying U.S. health care spending. Robert Wood Johnson Foundation. Research Synthesis Report No. 16. October 2008. Available at: http://www.rwjf. org/content/dam/farm/reports/issue_briefs/2008/rwjf32704/subassets/ rwjf32704_1. Accessed December 3, 2015.

5. Levine M, Buntin M. Why has growth in spending for fee-for-service Medicare slowed? Congressional Budget Office Working Paper 2013-06 August 22, 2013. Available at: https://www.cbo.gov/publication/44513. Accessed December 3, 2015.

6. Bundorf MK, Royalty A, Baker LC. Health care cost growth among the privately insured. Health Aff (Millwood). 2009;28(5):1294-304.

7. Health Care Cost Institute. Health care cost and utilization report: 2011 September 2012. Available at: http://www.healthcostinstitute.org/files/ HCCI_HCCUR2011.pdf. Accessed December 3, 2015.

8. Aetna. The facts about rising health care costs. 2012. See Figure: U.S healthcare spending breakdown, 2010. Available at: http://www.aetna.com/ health-reform-connection/aetnas-vision/facts-about-costs.html. Accessed November 22, 2015.

9. Schoenman J, Chockley N. The concentration of health care spending. NIHCM Foundation Data Brief. July 2012. Available at: http://www.nihcm. org/pdf/DataBrief3\%20Final.pdf. Accessed December 3, 2015.

10. Stanton MW, Rutherford MK. The high concentration of U.S. health care expenditures. Research in Action Issue 19. AHRQ Pub. No. 06-0060. 2005. Agency for Healthcare Research and Quality. Rockville, MD. Available at: http://meps.ahrq.gov/mepsweb/data_files/publications/ral9/ra19.pdf. Accessed December 3, 2015.

11. Cohen S, Uberoi N. Differentials in the concentration in the level of health expenditures across population subgroups in the U.S., 2010 Statistical Brief \#421. August 2013. Agency for Healthcare Research and Quality, Rockville, MD. Available at: http://meps.ahrq.gov/mepsweb/data_ files/publications/st421/stat421.shtml. Accessed November 22, 2015. 
12. Cornwell LJ, Cohen JW. Characteristics of persons with high medical expenditures in the U.S. civilian noninstitutionalized population, 2002. Statistical Brief \#73. March 2005. Agency for Healthcare Research and Quality, Rockville, MD. Available at: http://meps.ahrq.gov/mepsweb/data_ files/publications/st73/stat73.pdf. Accessed November 22, 2015.

13. Schoenman J, Chockley N. Understanding U.S. health care spending. NIHCM Foundation Data Brief. July 2011. Available at: http://www.nihcm.org/ images/stories/NIHCM-CostBrief-Email.pdf. Accessed December 3, 2015.

14. Khan $\mathrm{H}$. Why health care costs keep rising: what you need to know. $A B C$ News. March 9, 2010. Available at: http://abcnews.go.com/Politics/ HealthCare/health-care-costs-biggest-drivers/story?id=10044091. Accessed November 22, 2015

15. Express Scripts. Complex challenges, new solutions, 2010 drug trend report: a market and behavioral analysis. April 2011. Available at: https:// www.express-scripts.com/research/research/dtr/archive/2010/dtrFinal.pdf. Accessed November 22, 2015

16. IMS Institute for Healthcare Informatics. Healthcare spending among privately insured individuals under age 65. February 2012. Available at: http://www.imshealth.com/files/web/IMSH\%20Institute/Reports/ Healthcare\%20Spending\%20Among\%20Age\%2065/IHII_Spending_Report. pdf. Accessed November 22, 2015.

17. Al-Faruque F. Senators question cost of $\$ 1,000$ hepatitis drug. The Hill. July 11, 2014. Available at: http://thehill.com/policy/healthcare/211956wyden-grassley-bemoan-hep-c-drugs-high-cost. Accessed November 22, 2015.

18. American Society of Clinical Oncology. ASCO in action brief: value in cancer care. January 21, 2014. Available at: http://www.asco.org/advocacy/ asco-action-brief-value-cancer-care. Accessed November 22, 2015.

19. Congressional Budget Office. Offsetting effects of prescription drug use on Medicare's spending for medical services. November 2012. Available at: http://www.cbo.gov/publication/43741. Accessed November 22, 2015.
20. Tschida SJ, Aslam S, Lal LC, et al. Outcomes of a specialty pharmacy program for oral oncology medications. Am J Pharm Ben. 2012;4(4):165-74.

21. Schabert VF, Watson C, Gandra SR, Goodman S, Fox KM, Harrison DJ. Annual costs of tumor necrosis factor inhibitors using real-world data in a commercially insured population in the United States. J Med Econ. 2012;15(2):264-75.

22. Yeaw J, Lee WC, Aagren M, Christensen T. Cost of self-monitoring of blood glucose in the United States among patients on an insulin regimen for diabetes. J Manag Care Pharm. 2012;18(1):21-32. Available at: http://www. amcp.org/JMCP/2012/January-February/14481/1033.html.

23. Roos LL, Stranc L, James RC, Li J. Complications, comorbidities, and mortality: improving classification and prediction. Health Serv Res. 1997;32(2):229-38.

24. Healthcare Cost and Utilization Project (HCUP). Clinical Classifications Software for ICD-9-CM. December 2012. Available at: http://www.hcup-us. ahrq.gov/toolssoftware/ccs/ccs.jsp. Accessed November 22, 2015.

25. Basu A, Jena AB, Goldman DP, Philipson TJ, Dubois R. Heterogeneity in action: the role of passive personalization in comparative effectiveness research. Health Econ. 2014;23(3):359-73.

26. Landon BE, Zaslavsky AM, Saunders RC, Pawlson LG, Newhouse JP, Ayanian JZ. Analysis of Medicare Advantage HMOs compared with traditional Medicare shows lower use of many services during 2003-09. Health Aff (Millwood). 2012;31(12):2609-17.

27. Kaiser Health News. Table: Medicare spending by state and category. December 1, 2013. Available at: http://www.kaiserhealthnews.org/ Stories/2013/November/30/post-acute-care-table-by-state.aspx. Accessed November 22, 2015.

28. Hartman M, Martin AB, Benson J, Catlin A. National health spending in 2011: overall growth remains low, but some payers and services show signs of acceleration. Health Aff (Millwood). 2013;32(1):87-99. 